\title{
Awareness of health insurance in a urban population in Kolkata: A cross-sectional study
}

\author{
Dr. Stuti Sonthalia \\ DOI: 10.29322/IJSRP.11.09.2021.p11743 \\ http://dx.doi.org/10.29322/IJSRP.11.09.2021.p11743
}

\begin{abstract}
Health insurance is a growing segment in India. The Indian health system is one of the largest in the world, with the number of people it concerns: nearly 1.3 billion potential beneficiaries. Hence, health insurance is a rapidly emerging social security instrument that works on the basic principle of pooling of risks of unexpected costs of persons falling ill and needing hospitalization by charging premium from a wider population base of the same community. This study reports the awareness and utilization of health insurance by the urban people in Kolkata, India.

A total of 1000 samples were approached and among them, 324 volunteered for their responses. Of the 324 respondents, $308(94 \%)$ of them were aware of health insurance. Among 324 only $273(84 \%)$ had procured health insurance. Though this study shows increased prevalence of awareness of health insurance, there is still an alarming need to improve the awareness with regard to their knowledge about health insurance and the potential benefits amongst the community.
\end{abstract}

Index Terms- Awareness, Health, Insurance, Kolkata

\section{INTRODUCTION}

Health planners advocated for the expansion of health insurance as an essential component of India's healthcare reform and poverty reduction. However, enrolment to health insurance in India is still very limited. State-run mandatory health insurance schemes, namely, Central Government Health Scheme (CGHS) and Employees State Insurance Scheme (ESIS) are available for working people. Employer-based schemes are offered by public sector organizations such as railways, defense and security forces, mining sectors, and so on by offering medical services and benefits to the employee and his/her dependent family. Private insurance companies offer medical care insurance through individual subscriptions. For those who worked in the informal sector, community-based schemes and government sponsored

\section{RESULTS}

Of the 324 respondents, 308 (94\%) were aware about health insurance and $18(6 \%)$ were not aware about health insurance [Figure 1]. subsidized schemes are offered. Some NGOs also offer community-based health insurance or micro-insurance schemes. Accessing treatment from private providers leads to high household treatment costs. Healthcare costs are more impoverishing than ever before and almost all hospitalizations, including public hospitals lead to out of pocket health expenditures. Over 63 million people in India face poverty every year due to healthcare costs alone. Moreover, most of the underprivileged and the poor seek care from a variety of private healthcare providers, which incurs high treatment costs. This leads to catastrophic healthcare expenditures and it impoverishes the low- and middle-income class people. Equity in healthcare is emphasized on equal quality of care for all. Many countries considered social health insurance as financial mechanism to secure access to adequate healthcare for all at an affordable price. In India, health insurance is seen as one of the options in the absence of government's initiatives to provide quality and equitable healthcare through public hospitals. In this background, it is important to understand how far these schemes are popular among the people and their utilization among the respondents.

\section{METHODS AND MATERIALS}

The present study was carried out in the urban population of Kolkata. A questionnaire was presented to random people residing in the urban part of Kolkata city. All the local and state lockdown norms were followed during this survey. Forms were shared digitally to the volunteers using link of Google forms. A pretested semi-structured questionnaire was used for collecting data on socio-demographic characteristics of the study population and their awareness about the health insurance was recorded. The collected data was analyzed using percentages and proportion. A total of 1000 samples were approached and among them, 324 volunteered for their responses. 


\section{Aware about health insurance}

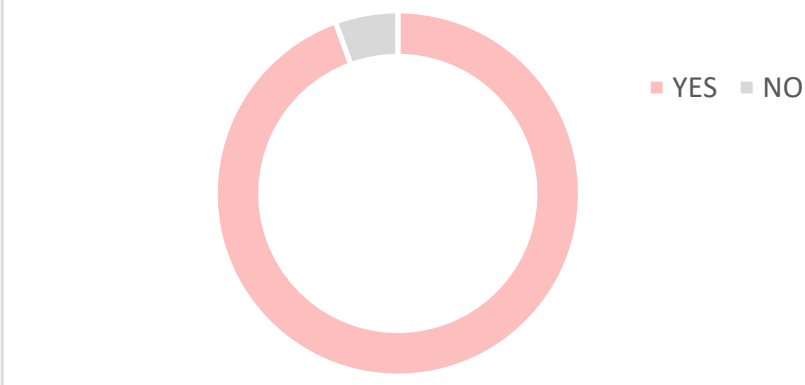

Figure 1: Percentage of people aware about health insurance

Most of the aware people had got the information regarding health insurance from family friends (267), internet (105), television (96), working place (84), and outdoor advertisements (51), hospitals (39) and other sources like newspapers (45). [Figure 2]

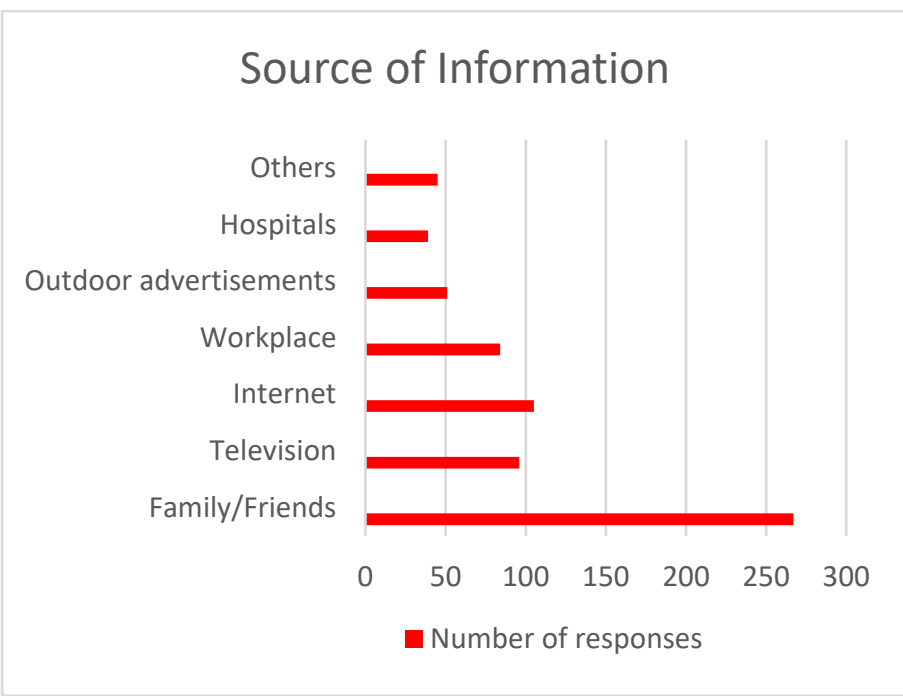

Figure 2: Source of Information about health insurance

Of the studied population, $273(84 \%)$ respondents had done their health insurance and $36(11 \%)$ did not have any insurance while $15(5 \%)$ were not sure about their insurance coverage. [Figure 3]

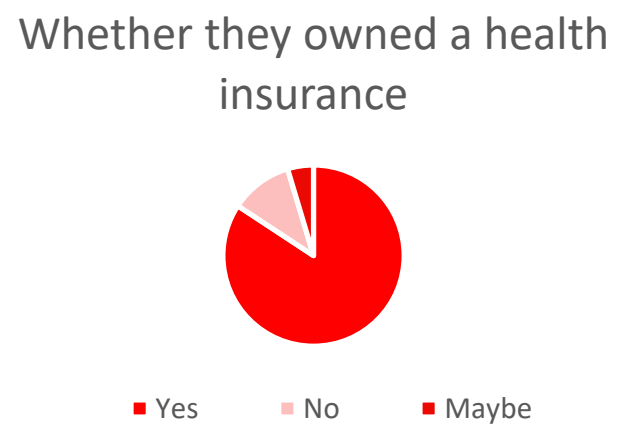

Figure 3: Number of people who owned a health insurance

This publication is licensed under Creative Commons Attribution CC BY.
Out of the 273 people who had health insurance, majority of them (44\%) opted 'better healthcare of the family' as the reason for taking a health insurance plan whereas $42 \%$ of the respondents said 'rising medical expenses' to be the main reason. [Figure 4]

\section{Reason for taking a health insurance}

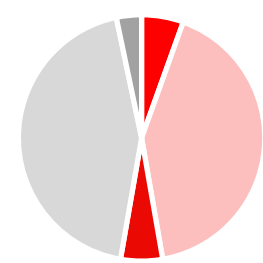

$$
\begin{aligned}
& \text { - Employee complulsion } \square \text { Rising medical expenses } \\
& \text { - Expecting health problems } \backsim \text { Better healthcare for family } \\
& \text { - Others }
\end{aligned}
$$

Figure 4: Reasons for opting a health insurance coverage

The graph [Figure 5] shows the benefits of health insurance. When questioned about these benefits, 213 of them answered that they were aware about the benefit of emergency healthcare, 171 of them were aware about better utilization of medical facilities, 150 knew about the income tax benefits, 120 were aware about the annual health check-ups and 96 were aware about the benefit of reduction in kit expenditure.

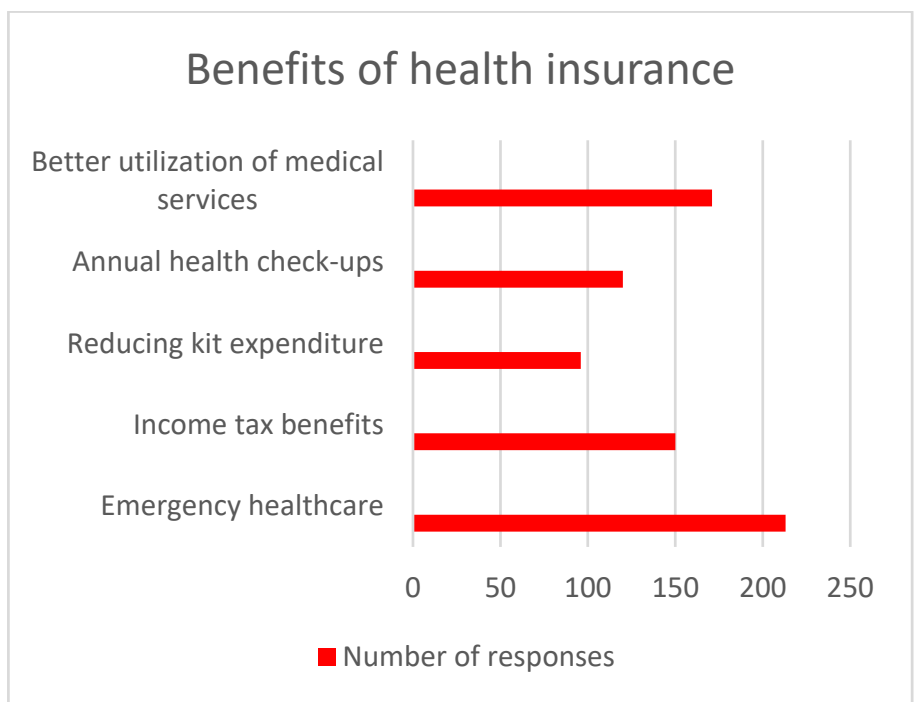

Figure 5: Awareness about benefits of health insurance

On questioning about major Central and West Bengal state health insurance coverage schemes [Figure 6], 93 (28.7\%) of them answered that they were not aware of any of the mentioned schemes. 


\section{Awareness about Central/State health coverage schemes}

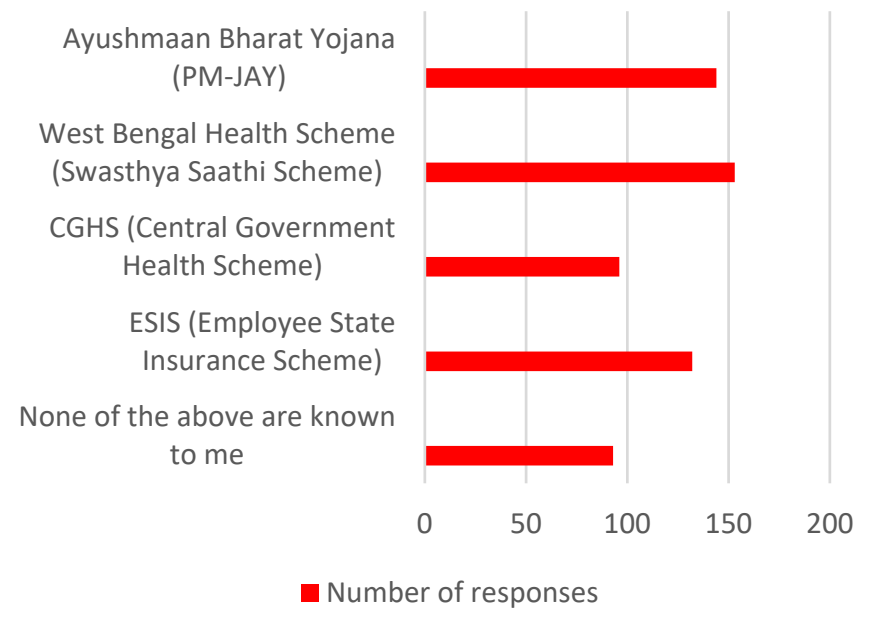

Figure 6: Awareness of the respondents regarding the various Central/ State health coverage schemes

Opinions of the respondents regarding health insurance hesitancy were recorded [Figure 7], in which majority of the people (34\%), answered that the high premiums that are charged is the major reason why people do not prefer taking a health insurance coverage.

\section{Opinions of respondents regarding health insurance hesitancy}

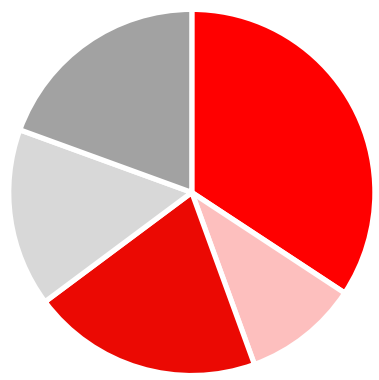

$$
\begin{aligned}
& \text { - High premiums charged } \quad \text { Poor service provided } \\
& \text { - No returns for investment } \quad \text { Shortage of disposable funds } \\
& \text { - Others }
\end{aligned}
$$

Figure 7: Opinions of respondents regarding health insurance hesitancy among people

\section{DISCUSSION}

This study is an effort in the area of health insurance to assess the individual's awareness level and to know the determinants of awareness. The prevalence of the awareness of health insurance among 324 study subjects was $94 \%$ whereas $84 \%$ people owned a health insurance plan. This study shows the increased prevalence of awareness which means media and government are fulfilling their responsibilities of creating awareness among the people about health insurance and also by making the process of making a health insurance policy easy and the sanctioning of the policy in crucial times easier and quicker. Various determinants have an impact on the awareness level. Awareness in this study was seen mainly through family and friends. A majority of the respondents $120(44 \%)$ had taken health insurance to provide better healthcare for their families while 114 $(42 \%)$ opted it because of the rising medical expenditures.

Most of the respondents (34\%) were of the opinion that high premiums charged by the companies was the major reason why people do not opt for a health insurance coverage, thus giving us a picture of the reasons behind less insurance penetration among the population. Benefits of the health insurance are vaguely understood by the respondents.

Since, $28.7 \%$ of the respondents did not know about the major central and state health schemes mentioned in the questionnaire, it can be said that there is a need to launch effective IEC activities to make them aware of the relevant schemes run by the government to meet the ever rising medical expenses and improve the utilization of the medical services.

\section{CONCLUSION}

Awareness of health insurance was found to be high (94\%) among studied population, though only $84 \%$ of them chose to own one. Thus, there is still a need to publicize the potential benefits of the insurance schemes and a better understanding of this is required. Major reasons like high premiums charged by the companies, less returns on investment, poor health services provided to insurance bearers, shortage of disposable funds should be taken into consideration and an increased penetration of the central \& state health coverage schemes must be aimed. An effective information, education, and communication activities can aid and improve the present understanding of the people.

\section{ACKNOWLEDGMENT}

The completion of this research survey could not have been possible without the participation and assistance of the volunteers. Their responses are sincerely appreciated and gratefully acknowledged.

\section{REFERENCES}

[1] (https://en.wikipedia.org/wiki/Health_insurance_in_India, n.d.)

[2] Government of India 2017 . Ministry of Health and Family Welfare, Government of India; 2017. National Health Policy.

[3] Gupta I, Guin P. Health status and access to health services in Indian slums. Health. 2015;7:245-55. doi: 10.4236/health.2015.72029

[4] Awasthi S, Pande VK. Family expenditure on sickness episodes of pre-school children in urban slums of Lucknow, North India. J Trop Paediatr. 1998;27:1-5

[5] Culyer AJ, Wagstaff A. Equity and equality in health and health care. J Health Econ. 1993;12:431-57

[6] Whitehead M. The concepts and principles of equity and health. Heal Promot Int. 1991;6:217-18. doi: 10.1093/heapro/6.3.217.

[7] Carrin G, James C. Reaching universal coverage via social health insurance: key design features in the transition period. Geneva: World Health Organization; 2004 
[8] K, Indumathi \& I, Hajira \& Gopi, Arun \& Subramanian, Mangala. (2016). Awareness of health insurance in a rural population of Bangalore, India. International Journal of Medical Science and Public Health. 5. 1. 10.5455/ijmsph.2016.15042016476.

[9] Kusuma YS, Pal M, Babu BV. Health Insurance: Awareness, Utilization, and its Determinants among the Urban Poor in Delhi, India. J Epidemiol Glob Health. 2018 Dec;8(1-2):69-76. doi: 10.2991/j.jegh.2018.09.004. PMID: 30859791; PMCID: PMC7325807.

\section{AUTHORS}

First Author - Dr.Stuti Sonthalia, B.D.S , drstutisonthalia@gmail.com 